\title{
PENYULUHAN TENTANG HIPERTENSI PADA LANSIA DAN PELATIHAN SENAM LANSIA
}

\author{
Nur Israyati, SST, M.Keb ${ }^{(1)}$, Yulrina Ardhiyanti, SKM, M.Kes ${ }^{(2)}$ \\ Ani Triana, SST, M.Kes ${ }^{(3)}$ \\ Email : nurisrayati@nurisrayati@gmail.com
}

\begin{abstract}
ABSTRAK
Lansia merupakan bagian dari anggota keluarga dan anggota masyarakat yang semakin bertambah jumlahnya sejalan dengan peningkatan usia harapan hidup. Peningkatan umur akan menyebabkan beberapa perubahan fisiologis, pada usia lanjut terjadi peningkatan resistensi perifer dan aktivitas simpatik. Tekanan darah akan meningkat setelah umur 45 - 55 tahun, dinding arteri akan mengalami penebalan oleh adanya penumpukan zat kolagen yang pada lapisan otot sehingga pembuluh darah akan berangsur-angsur menyempit menjadi kaku. Menurut Katzung (2010), pembatasan asupan natrium merupakan pengobatan efektif bagi banyak pasien hipertensi ringan. Pembatasan natrium dapat dilakukan dengan tidak memberi garam pada makanan selama atau sesudah masak dan dengan menghindari makanan yang diawetkan dengan natrium yang besar. Disamping itu, Senam lansia jug dapat dilakukan karena merupakan olahraga ringan dan mudah dilakukan, tidak memberatkan, yang diterapkan pada lansia. Aktifitas olahraga senam lansia membantu tubuh agar tetap bugar dan tetap segar karena melatih tulang tetap kuat, mendorong jantung bekerja optimal dan membantu menghilangkan radikal bebas yang berlebihan didalam tubuh Kegiatan penyuluhan tentang hipertensi pada lansia dan pelatihan senam lansia telah dilaksnakan pada hari senin 16 Januari 2017 bertempat di di Halaman Rumah Kadus 3 Bagan Laguh Kec.Bunut Kab.Pelalawan yang dihadiri warga setempat. Metode yang dilakukan dengan memberikan penyuluhan, handout, slide gambar dan video yang menarik serta tanya jawab tentang hipertensi pada lansia dan pelatihan senam lansia. Setelah dilakukan kegiatan pengabdian ini diharapkan masyarakat terutama para lansia dapat memahami materi yang diberikan mengenai hipertensi dan senam lansia, masyarakat terutama para lansia dapat mengaplikasikan pola hidup sehat serta senam lansia yang sudah didemonstrasikan.
\end{abstract}

\section{Kata Kunci : Hipertensi, Lansia, Senam Lansia}

\section{PENDAHULUAN}

Lansia merupakan bagian dari anggota keluarga dan anggota masyarakat yang semakin bertambah jumlahnya sejalan dengan peningkatan usia harapan hidup. Jumlah lansia meningkat diseluruh Indonesia menjadi 15,1 juta jiwa pada tahun 2000 atau 7,2\% dari seluruh penduduk dengan usia harapan hidup 64,05 tahun. Tahun 2006 usia harapan hidup meningkat menjadi 66,2 tahun dan jumlah lansia menjadi 19 juta orang, dan diperkirakan pada tahun 2020 akan menjadi 29 juta orang atau $11,4 \%$. Hal ini menunjukkan bahwa jumlah lansia 
meningkat secara konsisten dari waktu kewaktu (Riskesdas, 2013).

Masa usia lanjut ditandai dengan penurunan kondisi fisik sehingga lansia lebih mudahterserang penyakit, seperti perubahan kardiovaskuler. Terdapat beberapa macam penyakit yang biasa menimpa para lansia antara lain hipertensi, diabetes mellitus, jantung coroner, stroke, katarak, dan lain sebagainya. Macam-macam masalah kesehatan tersebut yang sering menimpa lansia yaitu hipertensi yang bisa menjadi awitan dari berbagai masalah kardiovaskuler lainnya yang lebih gawat (Jubaidi, 2008).

Hipertensi atau tekanan darah tinggi adalah tekanan sistolik lebih dari 140 $\mathrm{mmHg}$ dan tekanan darah diastolic lebih dari $90 \mathrm{mmHg}$. Hipertensi merupakan penyakit multifaktorial yang muncul oleh karena interaksi berbagai factor. Peningkatan umur akan menyebabkan beberapa perubahan fisiologis, pada usia lanjut terjadi peningkatan resistensi perifer dan aktivitas simpatik. Tekanan darah akan meningkat setelah umur 45 - 55 tahun, dinding arteri akan mengalami penebalan oleh adanya penumpukan zat kolagen yang pada lapisan otot sehingga pembuluh darah akan berangsur-angsur menyempit menjadi kaku (Setiawan, 2014).
Semakin tingginya usia hidup, maka semakin tinggi pula factor resiko terjadinya berbagai masalah kesehatan. Masalah umum yang dialami para lansia adalah rentannya kondisi fisik para lansia terhadap berbagai penyakit karena berkurangnya daya tahan tubuh dalam menghadapi pengaruh dari luar serta menurunnya efisiensi mekanisme hemostatis, oleh karena hal tersebut lansia mudah terserang berbagai penyakit (Riskesdas, 2013).

Menurut Katzung (2010), pembatasan asupan natrium merupakan pengobatan efektif bagi banyak pasien hipertensi ringan. Pembatasan natrium dapat dilakukan dengan tidak memberi garam pada makanan selama atau sesudah masak dan dengan menghindari makanan yang diawetkan dengan natrium yang besar. Bukti bahwa diet yang kaya buah dan sayuran dan dengan produk sedikit lemak juga efektif dalam menurunkan tekanan darah.

Beberapa studi terakhir ini menunjukkan bahwa kombinasi antara terapi tanpa obat (Non-Farmakoterapi) dengan obat (Farmakoterapi) tidak hanya menurunkan tekanan darah, namun juga menurunkan resiko stroke dan penyakit jantung iskemik.Terapi dengan obat bisa dilakukan dengan pemberian obat anti hipertensi, sedangkan terapi tanpa obat bisa dilakukan dengan berolahraga secara 
teratur, dari berbagai macam olahraga yang dapat dilakukan yaitu olahraga senam lansia (Armilawati, 2007).

Senam lansia merupakan olahraga ringan dan mudah dilakukan, tidak memberatkan, yang diterapkan pada lansia. Aktifitas olahraga senam lansia membantu tubuh agar tetap bugar dan tetap segar karena melatih tulang tetap kuat, mendorong jantung bekerja optimal dan membantu menghilangkan radikal bebas yang berlebihan didalam tubuh (Setiawan, 2014).

Maka perlunya dilakukan kegiatan pengabdian masyarakat tentang hipertensi dan pelatihan tentang senam lansia di Desa Bagan Laguh terlihat dari rendahnya pengetahuan masyarakat tentang hipertensi dan senam lansia. Penyuluhan yang diberikan berisi materi mencakup tentang hipertensi serta manfaat dari senam lansia bagi penderita hipertensi terutama bagi lansia.

\section{METODE KEGIATAN}

a. Penyampaian materi dimana para warga mendengarkan dan memahami apa yang di jelaskan mengenai hipertensi pada lansia.

b. Ceramah dan diskusi dilakukan agar masyarakat yang belum mengerti bisa lebih meningkatkan pengetahuan tentang hipertensi pada lansia, di harapkan agar setiap masyarakat dapat menerapkan pola hidup sehat.

c. Demontrasi dalam pelaksanaan senam lansia di mana para warga melihat dan mengikuti senam yang di intruksikan

\section{HASIL DAN PEMBAHASAN}

\section{Hasil Pelaksanaan}

Kegiatan penyuluhan tentang hipertensi pada lansia dan pelatihan senam lansia dilaksanakan pada hari Senin / 16 Januari 2017. Kegiatan yang diajarkan kepada peserta atau para lansia ini memberikan hasil sebagai berikut :

1. Tenaga Kesehatan

Berdasarkan hasil pelaksanaan penyuluhan hipertensi, pemeriksaan kesehatan dan senam lansia di Halaman Rumah Kadus 3 Bagan Laguh Kec.Bunut Kab.Pelalawan, sudah terlihat bahwa tenaga kader cukup berperan dalam kegiatan ini.

2. Masyarakat

Masyarakat terlihat antusias dengan kegiatan yang diadakan terlihat dari banyaknya masyarakat yang bertanya mengenai hipertensi dan senam lansia. Masyarakat mampu mengikuti senam lansia yang didemonstrasikan 


\section{PEMBAHASAN}

\section{A. Evaluasi.}

1. Standar Persiapan.
a. Menyiapkan penyuluhan.
b. Menyiapkan tempat.
c. Membagikan leafleat.

materi

2. Standar Proses.

a. Memberi penyuluhan dan menjelaskan materi penyuluhan.

b. Mengevaluasi kehadiran dan keaktifan peserta dari awal sampai akhir.

3. Evaluasi Hasil.

Untuk memberikan informasi tentang hipertensi pada lansia dan senam lansia .

\section{B. Faktor}

\section{Pendukung}

dan

\section{Penghambat.}

1. Faktor Pendukung.

Sarana dan prasarana yang disediakan serta koordinasi yang baik dengan pihak puskesmas.

2. Faktor Penghambat.

Keterbatasan $\begin{aligned} & \text { waktu dalam } \\ & \text { melakukan penyuluhan yang } \\ & \text { berkaitan dengan kegiatan }\end{aligned}$
pelayanan puskesmas sehingga
peserta penyuluhan yang hadir
tidak memenuhi target.

\section{KESIMPULAN}

Dari kegiatan pengabdian masyarakat yang telah dilakukan dapat disimpulkan bahwa :

1. Masyarakat terutama para lansia dapat memahami materi yang diberikan mengenai hipertensi dan senam lansia.

2. Masyarakat terutama para lansia dapat mengaplikasikan pola hidup sehat serta senam lansia yang sudah didemonstrasikan.

\section{DAFTAR PUSTAKA}

Armilawati, Amalia H. Amiruddin. 2007. Hipertensi dan Faktor Resikonya Dalam Keajadian Epidemiologi. Ujung Pandang : FKM UNHAS.

Katzung, B. G. 2010. Farmakologi Dasar dan Klinik. Jakarta : Salemba Medika. Price, S. A. \& Wilson, L. M. 2006. Patofisiologi Konsep Klinis Prosesproses Penyakit. Edisi 4. Jakarta : EGC.

Ruhyanudin, F. 2007. Asuhan Keperawatan pada Klien dengan Gangguan Sistem Kardiovaskular. Malang : UMM Press

Setiawan. 2014. Hubungan Frekuensi Senam Lansia Terhadap Tekanan Darah dan Nadi Pada Lansia Hipertensi. Semarang : PPNI 
Smeltzer \& Bare. 2010. Buku Ajar Keperawatan Medikal-Bedah. Jakarta : EGC.

Soeharto, I. 2007. Serangan Jantung dan Stroke Hubungannya dengan Lemak
\& Kolesterol. Edisi 2. Jakarta : PT Gramedia Pustaka Utama.

Sumintarsih. 2006. Kebugaran Jasmani Untuk Lansia. Olahraga. 147 - 160. Underwood, J. 2006. Patologi Umum dan Sistemik. Edisi 2. Jakarta : EGC 